\title{
Chromosomal evolution in Rattini (Muridae, Rodentia)
}

\author{
Daleen Badenhorst • Gauthier Dobigny • Filomena Adega • Raquel Chaves • \\ Patricia C. M. O'Brien • Malcolm A. Ferguson-Smith • Paul D. Waters • \\ Terence J. Robinson
}

Received: 28 June 2011 /Revised: 28 July 2011 /Accepted: 29 July 2011 / Published online: 18 August 2011

(C) Springer Science+Business Media B.V. 2011

\begin{abstract}
The Rattini (Muridae, Murinae) includes the biologically important model species Rattus norvegicus (RNO) and represents a group of rodents that are of clinical, agricultural and epidemiological importance. We present a comparative molecular cytogenetic investigation of ten Rattini species representative of the genera Maxomys, Leopoldamys, Niviventer, Berylmys, Bandicota and Rattus using chromosome banding, cross-species painting (Zoofluorescent in situ hybridization or FISH) and BACFISH mapping. Our results show that these taxa are
\end{abstract}

Responsible Editor: Herbert Macgregor

Electronic supplementary material The online version of this article (doi:10.1007/s10577-011-9227-2) contains

supplementary material, which is available to authorized users.

D. Badenhorst • T. J. Robinson ( $\triangle)$

Evolutionary Genomics Group, Botany and Zoology

Department, University of Stellenbosch,

Private Bag X1,

7604 Matieland, South Africa

e-mail: tjr@sun.ac.za

G. Dobigny

Centre de Biologie pour la Gestion des Populations

(UMR 022 INRA-IRD-CIRAD-SupAgro),

Campus de Baillarguet, CS30016,

34988 Montferrier-sur-Lez, France

G. Dobigny

Centre Régional Agrhymet,

Rive droite, BP1011, Niamey, Niger characterised by slow to moderate rates of chromosome evolution that contrasts with the extensive chromosome restructuring identified in most other murid rodents, particularly the mouse lineage. This extends to genomic features such as NOR location (for example, NORs on RNO 3 are present on the corresponding chromosomes in all species except Bandicota savilei and Niviventer fulvescens, and the NORs on RNO 10 are conserved in all Rattini with the exception of Rattus). The satellite I DNA family detected and characterised herein appears to be taxon

\footnotetext{
F. Adega $\cdot$ R. Chaves

Laboratório Associado Institute for Biotechnology and Bioengineering (IBB), Centre of Genomics and Biotechnology, University of Trás-os-Montes and Alto Douro (CGB-UTAD), P-5001-801,

Vila Real, Portugal

P. C. M. O'Brien • M. A. Ferguson-Smith

Department of Veterinary Medicine, University of Cambridge, Cambridge, UK

P. D. Waters

Evolution Ecology and Genetics, Research School of Biology, the Australian National University, Canberra, Australia
} 
(Rattus) specific, and of recent origin (consistent with a feedback model of satellite evolution). BACmapping using clones that span regions responsible for the morphological variability exhibited by RNO 1, 12 and 13 (acrocentric/submetacentric) and their orthologues in Rattus species, demonstrated that the differences are most likely due to pericentric inversions as exemplified by data on Rattus tanezumi. Chromosomal characters detected using $R$. norvegicus and Maxomys surifer whole chromosome painting probes were mapped to a consensus sequence-based phylogenetic tree thus allowing an objective assessment of ancestral states for the reconstruction of the putative Rattini ancestral karyotype. This is thought to have comprised 46 chromosomes that, with the exception of a single pair of metacentric autosomes, were acrocentric in morphology.

Keywords Chromosome painting · karyotype evolution · ancestral karyotype · satellite DNA . BAC-FISH $\cdot$ Rattini

$\begin{array}{ll}\text { Abbreviations } \\ \text { BAC } & \text { Bacterial artificial chromosome } \\ \text { BBE } & \text { Berylmys berdmorei } \\ \text { BBO } & \text { Berylmys bowersi } \\ \text { BSA } & \text { Bandicota savilei } \\ \text { COI } & \text { Cytochrome C oxidase I } \\ \text { DAPI } & \text { 4', 6-Diamidino-2-phenylindole } \\ \text { dist } & \text { Distal } \\ \text { FISH } & \text { Fluorescent in situ hybridisation } \\ \text { IHB } & \text { Interstitial heterochromatic block } \\ \text { IRBP } & \text { Interphotoreceptor retinoid-binding protein } \\ \text { LED } & \text { Leopoldamys edwardsi } \\ \text { LINE-1 } & \text { Long interspersed element-1 } \\ \text { MSU } & \text { Maxomys surifer } \\ \text { mya } & \text { Million years ago } \\ \text { my } & \text { Million years } \\ \text { NFU } & \text { Niviventer fulvescens } \\ \text { NOR } & \text { Nucleolar organizer region } \\ \text { prox } & \text { Proximal } \\ \text { RAK } & \text { Rattini ancestral karyotype } \\ \text { Rb } & \text { Robertsonian } \\ \text { rDNA } & \text { Ribosomal DNA } \\ \text { REX } & \text { Rattus exulans } \\ \text { RLO } & \text { Rattus losea } \\ \text { RNO } & \text { Rattus norvegicus } \\ \text { RRA } & \text { Rattus rattus } \\ \text { RTA } & \text { Rattus tanezumi } \\ & \end{array}$

\section{Introduction}

Rodents are highly valued as model organisms in physiology and biomedical research (Wilson and Reeder 2005). In addition, their role as reservoirs and vectors of human pathogens (see Meerburg et al. 2009 for recent review) has led to increased interest and recognition of the importance of understanding their systematics, ecology and evolution (Jansa and Weksler 2004). This is enhanced by the commensal nature of many species (Wolfe et al. 2007). For example, Rattus rattus, Rattus norvegicus and Rattus exulans colonized along the routes of human migration throughout the Indo-Pacific region, a pattern that has been elegantly illustrated for $R$. exulans, a species that is often found in close association with human settlements (Matisoo-Smith and Robins 2004). Moreover, many taxa are highly invasive in new areas of colonization-for example Rattus tanezumi in South Africa (Taylor et al. 2008; Bastos et al. 2011).

Rattini, the murid tribe that forms the focus of our investigation, comprises $>167$ species distributed among 34 genera (Wilson and Reeder 2005; see Table 2 in Lecompte et al. 2008). It harbours the biologically important model species, the Norway rat, $R$. norvegicus (Aplin et al. 2003), for which a vast amount of data, both genomic and immunogenetic, have been generated (see for example Aitman et al. 2008; Twigger et al. 2008). The other Rattini species have, however, attracted less attention. In particular, comparative studies of their karyotypes remain scarce. Although the relationship between mouse and rat genomes has been extensively investigated by chromosome painting (Grutzner et al. 1999; Guilly et al. 1999; Stanyon et al. 1999; Helou et al. 2001; Nilsson et al. 2001; Cavagna et al. 2002), somewhat surprisingly, no comparisons have been conducted between Rattus species and their allies.

The paucity of chromosomal data for the Rattini highlights a critical need for more extensive systematic research on this important group. The present study provides the first assessment of the mode and tempo of genome organization within these rodents. We present data showing: (1) the distribution of rat-specific centromeric repeats, telomeres and NORs in ten species representative of the genera Maxomys, Leopoldamys, Niviventer, Berylmys, Bandicota and Rattus, (2) the results of multidirectional chromosome painting summarized in comparative chromosome homology maps for these species and (3) the outcome of a bacterial artificial chromosome-fluorescent in situ hybridisation 
(BAC-FISH) analysis of the heteromorphic chromosomes RNO 1, 12-13 and their orthologues in $R$. tanezumi. These chromosomes correspond to pairs 1, 9 and 13 of Yosida and colleagues' Rattus karyotypic descriptions (Yosida et al. 1971a, b; Yosida 1976, 1977). Their variability in Rattus (specifically within $R$. rattus, $R$. norvegicus, Rattus losea, $R$. tanezumi, $R$. annadalei and $R$. muelleli) has been attributed to either short-arm heterochromatic amplification or pericentric inversions (Yosida et al. 1971a, b; Yosida and Sagai 1975; Yosida 1976, 1977).

\section{Materials and methods}

Tissue samples, cell culture, chromosome preparation, G-bands and Ag-NORs

We studied ten species representative of six of the 34 recognized genera (Table 1). Other than $R$. norvegicus, which was obtained commercially, all specimens originated from Thailand in the vicinity of the settlements
Loei $\left(17^{\circ} 29^{\prime} \mathrm{N}, 101^{\circ} 43^{\prime} \mathrm{E}\right)$, Kalasin $\left(16^{\circ} 49^{\prime} \mathrm{N}, 103^{\circ} 53^{\prime} \mathrm{E}\right)$ and Phrae $\left(18^{\circ} 09^{\prime} \mathrm{N}, 100^{\circ} 08^{\prime} \mathrm{E}\right)$. Importantly, the speciesspecific status of each specimen was unambiguously assessed using molecular typing (Pagès personal communication) as described in Pagès et al. (2010). This is particularly important in Rattini where some aspects of the taxonomy are still unclear. Our nomenclature follows the most recent revision of the group (Pagès et al. 2010).

Chromosome preparations were made from bone marrow after yeast stimulation (Lee and Elder 1980) or from fibroblast cell-cultures established from intercostal tissue following standard procedures. Chromosomes were identified by G-banding (Seabright 1971). The distribution of NORs was investigated using silver staining (Goodpasture and Bloom 1975; Barch 1997) on previously DAPI-banded slides.

Flow sorting, generation of chromosome-specific painting probes and Zoo-FISH experiments

Chromosome-specific painting probes were generated at the Cambridge Resource Centre for Comparative

Table 1 List of species and specimens included in the present investigation for both chromosome painting and repeat element (satellite I DNA, telomeres and NORs) analysis; sampling localities and grid references are provided for each locality

\begin{tabular}{|c|c|c|c|c|c|c|c|c|c|c|}
\hline Species & Specimen & Sex & Origin & Material & $2 n$ & $\begin{array}{l}\text { Zoo-FISH } \\
\text { analysis }\end{array}$ & BAC-mapping & $\begin{array}{l}\text { Telomeric } \\
\text { repeats }\end{array}$ & $\begin{array}{l}\text { Satellite DNA } \\
\text { analysis }\end{array}$ & Ag-NORs \\
\hline Rattus losea & $\mathrm{R} 4724$ & $\mathrm{~F}$ & Loei & $\mathrm{cc}$ & 42 & $\mathrm{X}$ & & $\mathrm{X}$ & $\mathrm{X}$ & $\mathrm{X}$ \\
\hline \multirow[t]{2}{*}{ Rattus tanezumi } & $\mathrm{R} 4003$ & $\mathrm{~F}$ & Kalasin & $\mathrm{bm}$ & 42 & $\mathrm{X}$ & $\mathrm{X}$ & & & \\
\hline & R4182 & $\mathrm{F}$ & Phrae & $\mathrm{bm}$ & 42 & $\mathrm{X}$ & & $\mathrm{X}$ & $X$ & $\mathrm{X}$ \\
\hline \multirow[t]{2}{*}{ Rattus exulans } & R4033 & $\mathrm{F}$ & Phrae & $\mathrm{bm}$ & 42 & $\mathrm{X}$ & & $\mathrm{X}$ & $\mathrm{X}$ & $\mathrm{X}$ \\
\hline & R 4035 & $\mathrm{~F}$ & Phrae & $\mathrm{bm}$ & 42 & $\mathrm{X}$ & & & & \\
\hline Rattus norvegicus ${ }^{\mathrm{a}}$ & / & $\mathrm{F}$ & South Africa & $\mathrm{cc}$ & 42 & & $\mathrm{X}$ & & $\mathrm{X}$ & \\
\hline \multirow[t]{2}{*}{ Bandicota savilei } & $\mathrm{R} 4143$ & $\mathrm{M}$ & Phrae & $\mathrm{bm}$ & 45 & $\mathrm{X}$ & & & & \\
\hline & $\mathrm{R} 4408$ & $\mathrm{~F}$ & Loei & $\mathrm{cc}$ & 43 & $\mathrm{X}$ & & $\mathrm{X}$ & $\mathrm{X}$ & $\mathrm{X}$ \\
\hline Berylmys berdmorei & R4406 & $\mathrm{F}$ & Loei & $\mathrm{cc}$ & 41 & $\mathrm{X}$ & & $\mathrm{X}$ & $\mathrm{X}$ & $\mathrm{X}$ \\
\hline Berylmys bowersi & $\mathrm{R} 4400$ & M & Loei & $\mathrm{cc}$ & 40 & $\mathrm{X}$ & & $\mathrm{X}$ & $\mathrm{X}$ & $\mathrm{X}$ \\
\hline $\begin{array}{l}\text { Leopoldamys } \\
\text { edwardsi }\end{array}$ & R5239 & $\mathrm{M}$ & Loei & $\mathrm{cc}$ & 42 & $\mathrm{X}$ & & $\mathrm{X}$ & $\mathrm{X}$ & $\mathrm{X}$ \\
\hline $\begin{array}{l}\text { Niviventer } \\
\text { fulvescens }\end{array}$ & $\mathrm{R} 4519$ & $\mathrm{~F}$ & Loei & $\mathrm{bm}$ & 46 & $\mathrm{X}$ & & $\mathrm{X}$ & $X$ & $\mathrm{X}$ \\
\hline Maxomys surifer ${ }^{\mathrm{b}}$ & R4404 & M & Loei & $\mathrm{cc}$ & 52 & $\mathrm{X}$ & & $\mathrm{X}$ & $X$ & $X$ \\
\hline
\end{tabular}

Specimen numbers refer to the CBGP Asian rodent collection (Montpellier, France). Diploid (2n) number and type of biological material used ( $b m$ bone marrow; $c c$ cell culture) are indicated for each specimen

${ }^{a}$ The $R$. norvegicus specimen was obtained commercially and its precise origin is unknown

${ }^{\mathrm{b}}$ The $M$. surifer specimen used for the production and characterisation of flow-sorted chromosome paints

(/) not applicable 
Genomics, UK, from flow-sorted $R$. norvegicus (RNO, Stanyon et al. 1999) and Maxomys surifer fibroblasts (MSU, present study) on AT/GC ratio and size. The DNA was amplified using 6-MW primers by degenerate oligonucleotide primed PCR (DOP-PCR; Telenius et al. 1992) and fluorescently labelled with biotin and/or digoxigen-dUTP (Roche). Flow-sorted peaks were assigned by hybridizing each fluorescently labelled flow-sort to DAPI-banded metaphase chromosome spreads of the species of origin. Interspecific Zoo-FISH experiments were conducted in order to establish comparative chromosomal maps between the Rattini species. This involved reciprocal painting between MSU and RNO and unidirectional painting experiments using RNO and MSU paints to detect regions of synteny between these species and $R$. exulans (REX), $R$. tanezumi (RTA), $R$. losea (RLO), Bandicota savilei (BSA), Berylmys berdmorei (BBE), Berylmys bowersi (BBO), Leopoldamys edwardsi (LED) and Niviventer fulvescens (NFU). Hybridization of chromosome paints followed Gilbert et al. (2006) except that chromosome preparations were denature by incubation in $70 \%$ formamide $/ 0.6 \times$ $\mathrm{SSC}$ solution at $65^{\circ} \mathrm{C}$ for $30 \mathrm{~s}-1 \mathrm{~min}$ (depending on the probe/target species used) rather than the 30-45 $\mathrm{s}$ at $70^{\circ} \mathrm{C}$ as originally described.

\section{BAC clone selection, preparation and BAC-FISH}

BAC clones (Table 2) were selected from the Wellcome Trust Sanger Institute Ensembl contigs (http://www. ensembl.org) and were obtained from the Children's Hospital Oakland-BACPAC Resources, Oakland, CA, USA (http://www.bacpac.chori.org). The BACs were selected to span the pericentromeric regions of chromosomes RNO 1, 12-13 that varied with respect the morphology of the orthologues in $R$. rattus, $R$. losea, $R$. tanezumi, $R$. annadalei and $R$. muelleli. The $R$. tanezumi specimen analysed here was heteromorphic (i.e. possessing an acrocentric and a submetacentric morph) for the three variable orthologous pairs. This allowed the rapid comparison of the two chromosomal morphs (acrocentric vs. submetacentric), and whether the orientation of the $\mathrm{BAC}$ clones was altered (i.e. due to an inversion) or retained (i.e. the chromosomal variation is the result of heterochromatic variation and/or centromeric shifts). BAC clones were received as bacterial LB agar stab cultures and were handled according to the supplier's instructions (http://www.bacpac.chori.org/ vectorsdet.htm). DNA $(\sim 1 \mu \mathrm{g})$ was extracted from each BAC clone using Wizard Plus SV Miniprep DNA purification system (Promega) and labelled by standard nick translation with either biotin- or digoxigenindUTP (Roche). BAC-FISH followed Gilbert et al. (2006) except that the chromosome preparations together with the probe-mix were denatured on a hot plate at $65^{\circ} \mathrm{C}$ for $3 \mathrm{~min}$, and hybridization took place overnight in a humid chamber at $37^{\circ} \mathrm{C}$. Posthybridization washes consisted of a first wash in $0.4 \times$ $\mathrm{SSC} / 0.3 \%$ Tween 20 for $5 \mathrm{~min}$ at $60^{\circ} \mathrm{C}$, followed by second wash in $2 \times \mathrm{SSC} / 0.1 \%$ Tween 20 for $1 \mathrm{~min}$ at room temperature. The remainder of the detection
Table 2 BAC clones used in the study with their positions on the rat ideogram, clone names and relevant accession numbers

The map positions were confirmed by both NCBI and UCSC genome browsers

(/) These BAC clones have not yet been fully sequenced, however, all BAC clones have had both ends sequenced (SP6 and T7)

\begin{tabular}{|c|c|c|c|c|c|c|}
\hline & \multirow[t]{2}{*}{ Number } & \multirow{2}{*}{$\begin{array}{l}\text { Chromosome } \\
\text { position }\end{array}$} & \multirow[t]{2}{*}{ Clone ID } & \multirow{2}{*}{$\begin{array}{l}\text { Accession } \\
\text { number }\end{array}$} & \multicolumn{2}{|c|}{ End accession number } \\
\hline & & & & & SP6 & $\mathrm{T} 7$ \\
\hline \multirow[t]{4}{*}{ RNO 1} & 1 & $1 \mathrm{p} 13$ & CH230-347 K17 & AC135531 & BZ154483 & BZ154484 \\
\hline & 2 & $1 \mathrm{p} 11$ & $\mathrm{CH} 230-99 \mathrm{D} 20$ & AC109433 & BH314535 & BH314564 \\
\hline & 3 & $1 q 11$ & CH230-365B17 & l & BZ116707 & BZ116708 \\
\hline & 4 & $1 \mathrm{q} 12$ & CH230-447 J17 & l & BZ248996 & BZ248997 \\
\hline \multirow[t]{4}{*}{ RNO 12} & 5 & $12 \mathrm{p} 12$ & $\mathrm{CH} 230-30 \mathrm{M} 1$ & / & BH293553 & BH293555 \\
\hline & 6 & $12 \mathrm{p} 11$ & $\mathrm{CH} 230-70 \mathrm{E} 3$ & l & BH273680 & BH273682 \\
\hline & 7 & $12 \mathrm{q} 11$ & CH230-IJ13 & AC095368 & BH297088 & BH297089 \\
\hline & 8 & $12 \mathrm{q} 12$ & CH230-204 G18 & AC123562 & BH366346 & ВH366347 \\
\hline \multirow[t]{4}{*}{ RNO 13} & 9 & $13 \mathrm{p} 13$ & $\mathrm{CH} 230-52 \mathrm{~N} 12$ & AC103093 & BH318049 & BH318051 \\
\hline & 10 & $13 \mathrm{p} 11$ & CH230-231 G7 & l & BZ113582 & BZ113584 \\
\hline & 11 & $13 q 11$ & CH230-221 F10 & l & BH353297 & BZ094368 \\
\hline & 12 & $13 \mathrm{q} 12$ & $\mathrm{CH} 230-128 \mathrm{D} 5$ & AC106070 & BH279605 & BH279609 \\
\hline
\end{tabular}


protocol was carried out as previously described. Images were captured with a CCD camera coupled to an Olympus BX60 fluorescence microscope and analysed using Genus Imaging Software (Applied Imaging). Signals were assigned to specific chromosomes according to morphology, size and DAPI banding.

Detection of telomeres by fluorescent in situ hybridization

A telomeric probe containing the repeat motif (TTAGGG) $)_{n}$ was constructed and biotin-labelled by PCR as described by Ijdo et al. (1991). This probe was hybridized to metaphase chromosomes of nine species (see Table 1) within Rattini following the protocol described below for satellite DNA (satDNA).

DNA extraction, Satellite I DNA probe isolation and sequencing

Genomic DNA (gDNA) was extracted from tissue samples and/or pelleted fibroblasts of ten species (see Table 1) using the QIAamp DNA Micro kit (Qiagen) following manufacturers' instructions. PCR primers (forward: 5'-TCCCAGTAGCCTGCTCTTGT-3' and reverse: 5'-TCAGTTCGTTAAAACGTTGCTC -3') were designed according to the $R$. norvegicus satellite I DNA (sat I DNA) sequences available in the NCBI database (acc. no: V01570 J00784). PCR amplification was performed using $50 \mu \mathrm{l}$ reaction mixture that contained 100-300 ng gDNA, 10× buffer, $25 \mathrm{mM}$ $\mathrm{MgCl}_{2}, 2.5 \mathrm{mM} \mathrm{dNTPs}, 10 \mu \mathrm{M}$ of each forward and reverse primer, and $5 \mathrm{U}$ Taq. Cycling parameters entailed an initial denaturing step of $94^{\circ} \mathrm{C}$ for $3 \mathrm{~min}$ followed by 25 cycles at $94^{\circ} \mathrm{C}$ for $45 \mathrm{~s}, 55 / 62^{\circ} \mathrm{C}$ for $45 \mathrm{~s}$ and $72^{\circ} \mathrm{C}$ for $1 \mathrm{~min} 30 \mathrm{~s}$. A final extension of $72^{\circ} \mathrm{C}$ for $10 \mathrm{~min}$ completed the programme. PCR products were electrophoresised in 1\% agarose gels, excised and purified using the Wizard SV Gel and PCR Clean-up System (Promega) following the manufacturer's recommendations. Cycle-sequencing reactions were performed using BigDye Chemistry and products were analysed on an automated sequencer (AB 3100, Applied Biosystems). Nucleotide sequences were edited and aligned using ClustalW Multiple Alignment in Bioedit v. 7.0.9.0 (Hall 1999). DNA sequences were compared to those in the EMBL and Genbank database using BLASTN searches. Size of the repeats and their substructure was established using Tandem Repeat Finder (TRF) v 4.00 (Benson 1999).

Labelling of the PCR products for FISH was with either digoxigen-11-dUTP (Roche) or biotin-16-dUTP (Roche) using $5 \mu$ l buffer $(10 \times), 2 \mu \mathrm{l} \mathrm{MgCl}_{2}$ (25 mM), $5 \mu \mathrm{ldACG}(2.5 \mathrm{mM}), 1.5 \mu \mathrm{d}$ dUTP-biotin or DIG $(1 \mathrm{mM}), 5 \mu \mathrm{l}$ of each forward and reverse primer $(10 \mu \mathrm{M}), 1 \mu \mathrm{l}$ Taq $(5 \mathrm{U}), 5 \mu \mathrm{l}$ DNA (PCR product of the first amplification). This was made up to a final volume of $50 \mu \mathrm{l}$ with $\mathrm{dH}_{2} \mathrm{O}$. The PCR programme selected was the same as for the first round of amplification specified above. FISH of satellite I DNA probes followed Chaves et al. (2002, $2003 \mathrm{a}, \mathrm{b})$ with the exception that the probe mixtures were denatured at $80^{\circ} \mathrm{C}$ for $10 \mathrm{~min}$ and cooled on ice rather than the $65^{\circ} \mathrm{C}$ specified in these publications.

Mapping the chromosome rearrangements onto a consensus molecular tree

A robust consensus phylogenetic tree for intergeneric relationships within Rattini was derived from published molecular studies that utilize different DNA markers including LINE-1 insertion sites (Verneau et al. 1997, 1998), mitochondrial (cytochrome b and CO1) as well as nuclear (IRBP, syndecan-4) genes (Lecompte et al. 2008; Pagès et al. 2010; Badenhorst 2011). These show (1) Maxomys as a basal lineage within Rattini followed by (2) a Niviventer +Leopoldamys clade, then (3) a sister grouping of Berylmys and Bandicota+Rattus (Fig. 1).

Chromosomal differences (characters) inferred from the cross-species chromosome painting results were mapped to this topology. Published data on $R$. rattus (Cavagna et al. 2002) was included in the analysis. To facilitate the comparisons of banding patterns among taxa only intrachromosomal rearrangements involving segments that were conserved as whole syntenies/ chromosomes in Rattini were included. This allowed us to determine the polarity as well as the mode and tempo of karyotypic evolution in the various Rattini lineages. In terms of the latter, the rate of change was calculated using the ratio between the number of chromosome rearrangements and time of divergencethe latter inferred from molecular analyses that included representatives of each murine genus investigated in this study (Lecompte et al. 2008; Robins et al. 2008). The mapping of chromosomal characters onto the consensus tree permitted the identification of autapomorphies, synapomorphies, hemiplasies and homopla- 


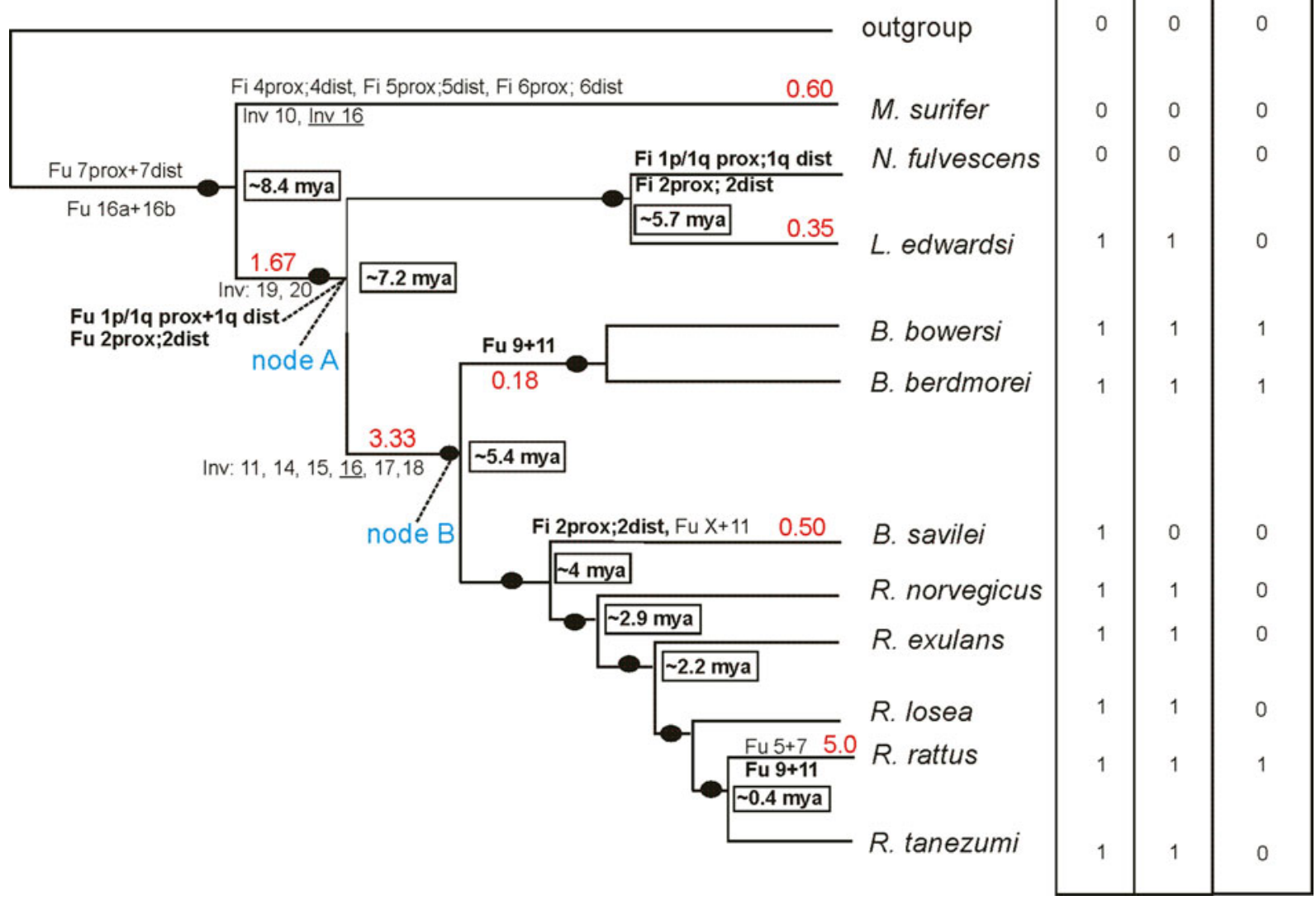

Fig. 1 Mapping of the chromosome changes (as inferred from Zoo-FISH experiments) to the Rattini molecular phylogenetic tree (modified from Verneau et al. 1997; Lecompte et al. 2008; Pagès et al. 2010; Badenhorst 2011) and the rates of chromosome evolution against divergence times. The numbering of rearrangements corresponds to the chromosomes of $R$. norvegicus. Numbers in squares indicate molecular divergence estimates in million years (mya) as inferred by Lecompte et al. (2008) and Robins et al. (2008). Numbers in red represent the average rates

sies associated with the grouping of various species. Finally, the topology was used to reconstruct ancestral characters at each node thus providing insights to the Rattini ancestral karyotype (RAK).

\section{Results}

G-banded karyotypes and Ag-NORs

The G-banded karyotypes of the Rattini species included in this study have previously been described (Badenhorst et al. 2009). Diploid numbers vary from 40 to 52 (i.e. $B$. of rearrangement per million years. $F u$ fusion, $F i$ fission, Inv pericentric inversion, dist distal, prox proximal, $a$ and $b$ refer to unidentifiable chromosomal segments resulting from the uncertain location of the breakpoint. Black ovals indicate strong nodal support $(\mathrm{BI}>0.95 ; \mathrm{BP}>95)$. Underlined chromosome numbers indicates two different breakpoints involving the inversion of the RNO 16 ortholog and homoplasic characters are denoted in bold. Columns on right demonstrate the presence (1) or absence $(0)$ of the $F u 1, F u 2$ and $R b 9+11$ rearrangements

bowersi $2 n=40, B$. berdmorei $2 n=41, B$. savilei $2 n=43$, $N$. fulvescens $2 n=46, M$. surifer $2 n=52$ ) with four of the species ( $R$. exulans, $R$. tanezumi, $R$. losea and $L$. edwardsi) characterised by an invariant $2 n=42$, a diploid number identical to that of $R$. norvegicus (Hamta et al. 2006; Badenhorst et al. 2009).

Silver staining detected a variable number of NORbearing autosomal chromosome pairs (Table 3 and supplementary material S1). For example, two NOR pairs were identified in B. savilei and eight in $M$. surifer. $N$. fulvescens and L. edwardsi both show five NOR-bearing chromosome pairs, and both $B$. bowersi and $B$. berdmorei are characterised by four pairs. 
Rattus exulans, R. losea and R. tanezumi all contained three NOR-bearing chromosome pairs, a finding that is consistent with data on $R$. norvegicus (Szabo et al. 1978; Kodama et al. 1980; Sasaki et al. 1986; Cavagna et al. 2002; see Table 3 present study). There is strong conservation of NOR location among species. For example, the NORs on RNO 3 are present on the corresponding chromosomes in all species except $B$. savilei and $N$. fulvescens, and the NORs on RNO 10 are conserved in all Rattini with the exception of Rattus. The remaining NOR loci are present in a minimum of two species, while those on RNO 5 are autapomorphic in M. surifer. The NOR locus on RNO 11 appears to be characteristic of the Rattus group but, importantly, is absent in R. rattus.

Detection of telomeres by fluorescent in situ hybridization

As expected the telomeric (TTAGGG) ized to the termini of all the chromosomes in the species investigated (supplementary material S2), an observation that is consistent with reports that these structures are crucial for maintaining the stability of chromosomes (Bolzan and Bianchi 2006, among others). In only one instance was a non-terminal
TTAGGG signal detected - at the centromeric region of pair 4 of $M$. surifer (supplementary material S2). There was no evidence to suggest its involvement with any of the chromosomal rearrangements identified in this study (see below). Additionally, interstitial telomeric signals were not detected at the B. savilei $\mathrm{X}$ autosome translocation junction, or at the sites of the head-to-head (Robertsonian, $\mathrm{Rb}$ ) fusion chromosomes in $B$. bowersi and B. berdmorei (supplementary material S2).

\section{Satellite I DNA analysis}

Sequences were obtained from the amplified PCR products for all species of Rattus (i.e. $R$. exulans, $R$. losea and $R$. tanezumi) as well as for $N$. fulvescens, $B$. savilei and $B$. berdmorei. However, sequencing of the PCR products from $M$. surifer, L. edwardsi and $B$. bowersi proved problematic and these species had to be excluded from further sequence analysis. Although clear sequences could be obtained for B. savilei, N. fulvescens and $B$. berdmorei, no homology could be found between them and sat I DNA of $R$. norvegicus following BLASTN analysis, and no internal substructure was identified using TRF (data not shown). Moreover pair-wise comparisons between these non-

Table 3 Number of chromosome pairs showing nucleolar organizer regions (NORs) in the nine species analysed in the

karyotypes; Badenhorst et al. 2009), including $R$. norvegicus and $R$. rattus from published data (Cavagna et al. 2002) present study (numbering according to their respective G-banded

\begin{tabular}{|c|c|c|c|}
\hline & No. NORs pairs & Chromosome no. & Respective $R$. norvegicus ortholog ${ }^{\mathrm{a}}$ \\
\hline R. exulans $(2 n=42, \mathrm{XX})$ & 3 & REX 3, 11 and 12 & 3,11 and 12 \\
\hline R. losea $(2 n=42, \mathrm{XX})$ & 3 & RLO 3, 11 and 12 & 3,11 and 12 \\
\hline R. tanezumi $(2 n=42, \mathrm{XX})$ & 3 & RTA 3, 11 and 12 & 3,11 and 12 \\
\hline B. savilei $(2 n=43, \mathrm{XX})$ & 2 & BSA 10 and 20 & 10 and 12 \\
\hline B. bowersi $(2 n=40, \mathrm{XY})$ & 4 & $\mathrm{BBO} 4,7,10$ and 9 & $3,6,8$ and 10 \\
\hline B. berdmorei $(2 n=41, \mathrm{XX})$ & 4 & $\mathrm{BBE} 4,7,10$ and 9 & $3,6,8$ and 10 \\
\hline L. edwardsi $(2 n=42, \mathrm{XY})$ & 5 & LED $2,3,4,10$ and 20 & $1,4,3,10$ and 12 \\
\hline N. fulvescens $(2 n=46, \mathrm{XX})$ & 5 & NFU $1,6,8,9$ and 10 & 1q dist, $6,8,9$ and 10 \\
\hline M. surifer $(2 n=52, \mathrm{XY})$ & 8 & MSU $1,2,4,6,7,14,17$ and 19 & $1 \mathrm{q}$ dist, 3,2 dist, $8,9,10,5$ dist and 6 prox \\
\hline R. norvegicus $(2 n=42)^{\mathrm{b}}$ & 3 & RNO 3, 11 and 12 & l \\
\hline R. rattus $(2 n=38)^{\mathrm{b}}$ & 2 & RRA 5,8 and 16 & RNO 3, 8 and 12 \\
\hline
\end{tabular}

${ }^{\text {a }}$ Correspondence to $R$. norvegicus orthologous chromosomes identified by cross-species chromosome painting using $R$. norvegicus paints

${ }^{\mathrm{b}}$ Based on silver staining

(/) not applicable 
Rattus species similarly showed no meaningful homology, and the characteristics of these sequences remain to be elucidated.

There was, however, significant homology between the $R$. norvegicus sat I DNA sequence available on Genbank and those obtained for $R$. exulans (97\%), $R$. losea $(91 \%)$ and $R$. tanezumi $(90 \%)$ in the present study (Fig. 2). In addition, a largely conserved 92-bp reiterated subunit was identified in the three Rattus species investigated here through the TRF analysis (supplementary material S3). Pair-wise comparisons between the $R$. norvegicus $92-\mathrm{bp}$ repeat subunit and $R$. exulans, $R$. losea and $R$. tanezumi 92-bp subunits, indicated $83 \%$ nucleotide similarity with $R$. exulans, $77 \%$ similarity with $R$. losea and 75\% sequence similarity with $R$. tanezumi. Similarly, pair-wise comparisons between $R$. losea with $R$. exulans and with $R$. tanezumi indicated $89 \%$ and $86 \%$ nucleotide similarity, respectively. Pair-wise comparison between $R$. exulans and $R$. tanezumi showed $86 \%$ sequence similarity.

Physical mapping of the labelled PCR products generated by the sat I DNA primers was conducted using FISH. The isolated non-Rattus sequences (B. savilei, B. berdmorei and $N$. fulvescens) resulted in an interspersed FISH pattern in both heterologous (i.e. between species) and autologous (i.e. within species) painting experiments (supplement file S2) emphasizing the lack of colocalization with evolutionary breakpoints identified through Zoo-FISH analysis using RNO and MSU paints. In addition, no clear hybridization signal could be obtained in heterologous painting experiments using Rattus PCR products against the chromosomes of the
non-Rattus species (B. savilei, B. bowersi, B. berdmorei, $N$. fulvescens, L. edwardsi and M. surifer).

In sharp contrast, hybridization patterns of sequences isolated from $R$. exulans, $R$. losea and $R$. tanezumi were invariably centromeric following autologous painting experiments. Similar patterns (centromeric) were identified in heterologous painting schemes using $R$. losea isolated satellite sequence as representative of the Rattus group against chromosomes of Rattus (supplementary material S2).

\section{FISH with BACs}

The order of BAC clones located on the q arm of RNO is unchanged in the acrocentric and submetacentric variants of RTA 1, 12 and 13 (that correspond to RNO 1, 12 and 13) indicating they fall outside of the region responsible for the differing morphologies of these chromosomes in $R$. tanezumi. Importantly, however, the order of the BAC clones selected for their positions on the submetacentric form of RNO 1, 12 and 13 are inverted in the acrocentric form of the heteromorphic pairs RTA 1, 12 and 13 of $R$. tanezumi (Fig. 3). For example, the order of the BAC clones on the $\mathrm{p}$ arm (from the terminal segment to the proximal segment of the submetacentric RNO 12) is: BAC clone 5 (12p12-Cy3) followed by BAC clone 6 (12p11-FITC), whereas the order is inverted in the R. tanezumi acrocentric morph (Fig. 3a). This pattern clearly confirms that the changes in morphology of these chromosomes are due to pericentric inversions in the three pairs and are not attributable to centromeric shifts, transposition or heterochromatic

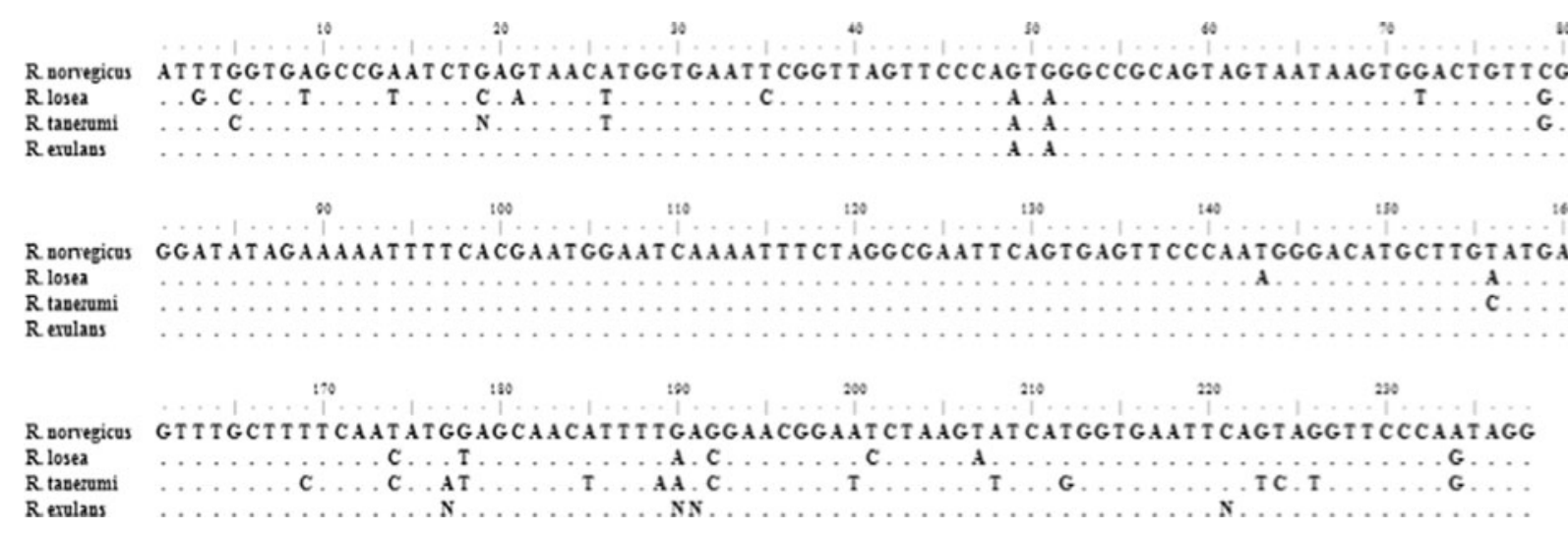

Fig. 2 Multiple alignment of four Rattus sat I DNA sequences (238 bp) displaying significant homology by ClustalW. Dots indicate identity with the $R$. norvegicus sat I DNA sequence 

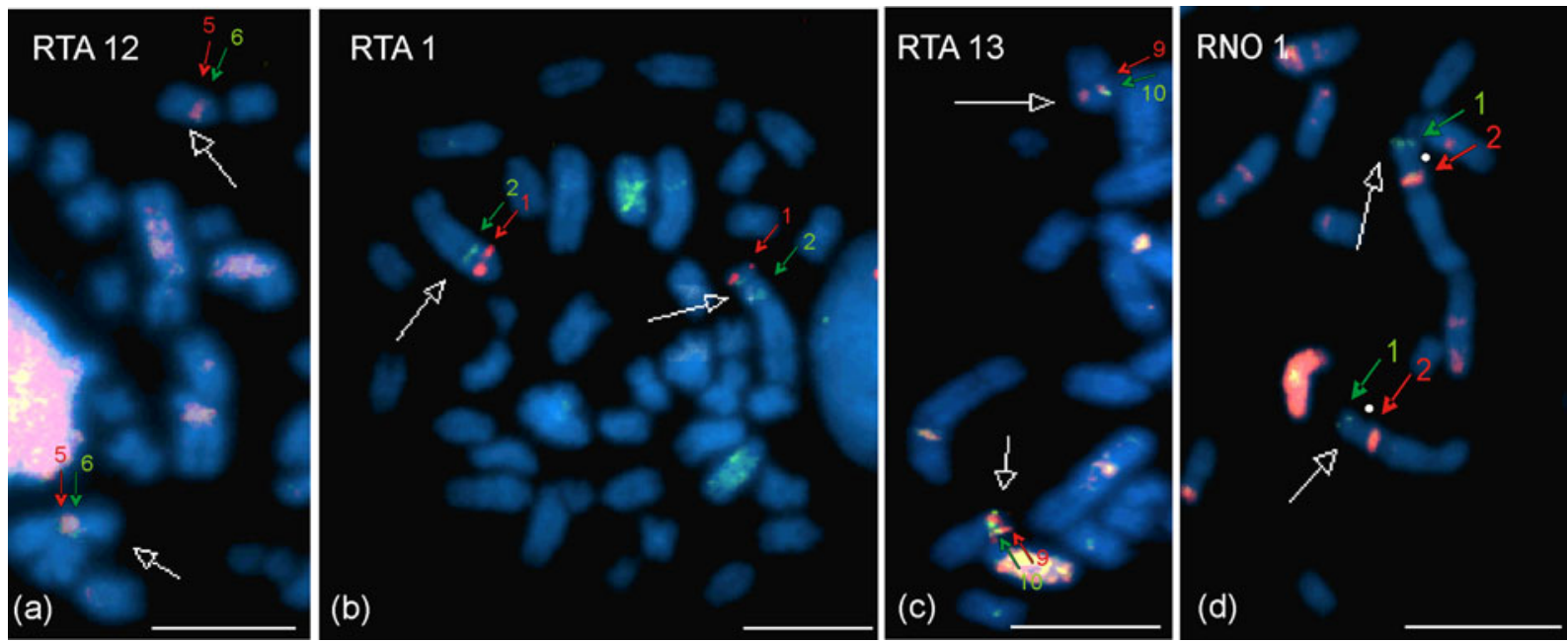

Fig. 3 a, b and $\mathbf{c}$ Representative metaphase spreads from a $R$. tanezumi specimen that is heterozygous for the acrocentric and submetacentric morphs of chromosome orthologous to RNO 1, 12, 13 (white arrows). Green and red arrows indicate the localization of BAC clones that map to $R$. norvegicus (RNO) $12 \mathrm{p}$ (BAC clone 5 red, BAC clone 6 green) (a); RNO 1p (BAC clone 1 red, BAC clone 2 green) (b); RNO 13p (BAC clone 9 red, BAC clone 10 green) (c). d Representative metaphase

arm variability in these Rattus species (Fig. 3a-c). In addition, these data permit a correction to the Ensembl database which gives the position of $R$. norvegicus BAC clone 2 at RNO 1p11 in contradiction to RNO 1q11 as evidenced by our FISH mapping data (Fig. 3d), raising the possibility that the sequenced individual may have had a structural polymorphism.

Flow-sorting and characterisation of painting probes

The $M$. surifer karyotype $(2 n=52, \mathrm{XY})$ resolved into 20 peaks (Fig. 4). Twelve contained a single chromosome (MSU 1, 2, 4, 7, 14, 17, 19-21, 24, Y) with MSU 4 identified in two separate peaks. This most likely reflects differing amounts of heterochromatin between the two homologs, although this was not readily apparent on C-band analysis. Seven peaks contained a mix of two different chromosomes (MSU $\mathrm{X}+4,5+6,8+9,11+13,10+15,22+25$ and $3+12)$, and one peak contained a mix of three chromosomes (MSU $16+18+23$ ). The assignment of one of the seven peaks containing two different chromosomes by FISH was unsuccessful as this peak failed to hybridize. It is assumed that MSU 3 and 12, which spread of $R$. norvegicus (RNO) showing localization of BAC clones on chromosome pair 1 (white arrow), centromere position indicated by white oval. The BAC clone selected for $1 \mathrm{p} 13$ (BAC clone 1, green) confirms the assignment given in Ensembl database while BAC clone 2, reportedly mapping to RNO1p11 by Ensembl, is located on the q arm (approximately $1 \mathrm{q} 11$ ) in both $R$. norvegicus and $R$. tanezumi. Scale bar= $10 \mu \mathrm{m}$. See text for details

were not present in any of the other flow sorts, were present in this peak. We were consequently unable to clarify breakpoints identified by $R$. norvegicus Zoo-

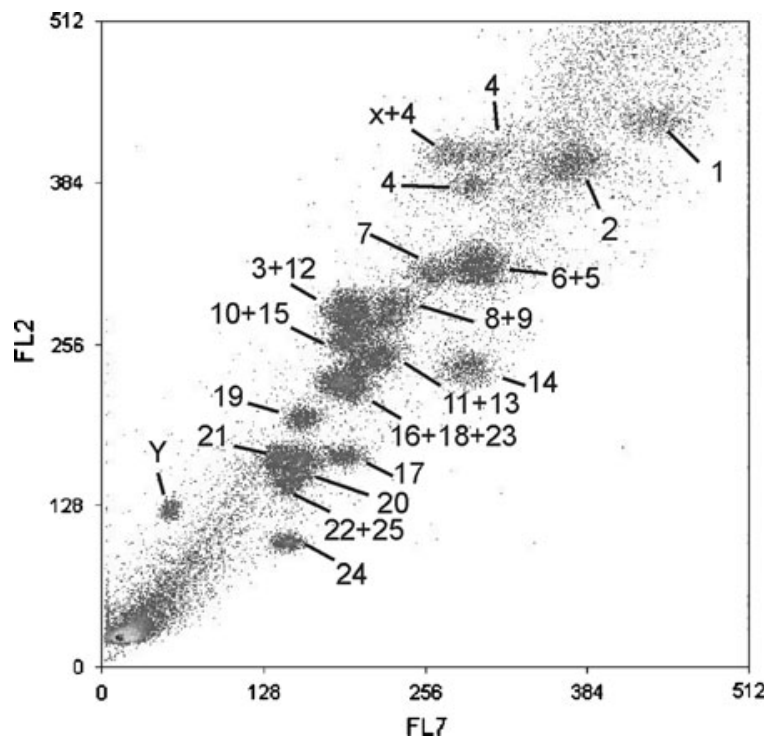

Fig. 4 Flow-sorted karyotypes of M. surifer (MSU, 2n=52, $\mathrm{XY}$ ) showing the flow-peaks and their correspondence with the respective chromosomes (see text for details) 
FISH that involved orthologues of MSU 3 and 12 (see below), but we were able to resolve these ambiguities using G-band comparisons.

As detailed by Stanyon et al. (1999), the $R$. norvegicus $(2 n=42)$ flow karyotype comprised 21 individual peaks of which two contained more than one chromosome-specifically RNO $11+15$ and RNO $13+14+15$. Importantly, RNO 15 is common to both peaks and therefore two-colour FISH can be used for differentiating between non-pure sorts involving RNO 15 from RNO 11, 13 and 14. The identification of RNO 13 and 14 could not be unambiguously clarified using either $M$. surifer chromosome paints or dual-colour FISH since their orthologues were contained in non-pure flow sorts. Fortunately, however, both chromosomes are easily distinguished on G-band patterns.

Reciprocal chromosome painting between MSU and RNO

The results of the cross-species chromosome painting of $R$. norvegicus chromosome paints onto $M$. surifer chromosomes are shown in Fig. 5. Sixteen $R$. norvegicus chromosomes ( $\mathrm{RNO} 3,7-20$ and $\mathrm{X}$ ) are conserved in toto in the $M$. surifer karyotype. Five $R$. norvegicus chromosomes each produced two signals (RNO 1, 2, 4, 5 and 6).

The reciprocal analysis of $M$. surifer whole chromosome paints to $R$. norvegicus chromosomes confirmed the unidirectional assignments based on painting $R$. norvegicus probes to M. surifer (Fig. 5) permitting a more precise delimitation of subchromosomal homologies in $M$. surifer. Importantly, the $M$. surifer chromosome paints proved useful for delimiting most breakpoints identified by the $R$. norvegicus Zoo-FISH analysis. The only exception was the disruption of RNO 2, since MSU 3 is presumed to be present in a peak that failed to hybridize when conducting the flow-sort assignments (see above). Thus, cross-hybridization to delimit breakpoint junctions in RNO 2 was only possible using the M. surifer probe corresponding to MSU 4. It seems reasonable to assume based on G-band comparisons and hybridisation of MSU 4, however, that the breakpoints are identical in all three genera (M. surifer, $N$. fulvescens and B. savilei), at least at the level of resolution permitted by FISH. (a)

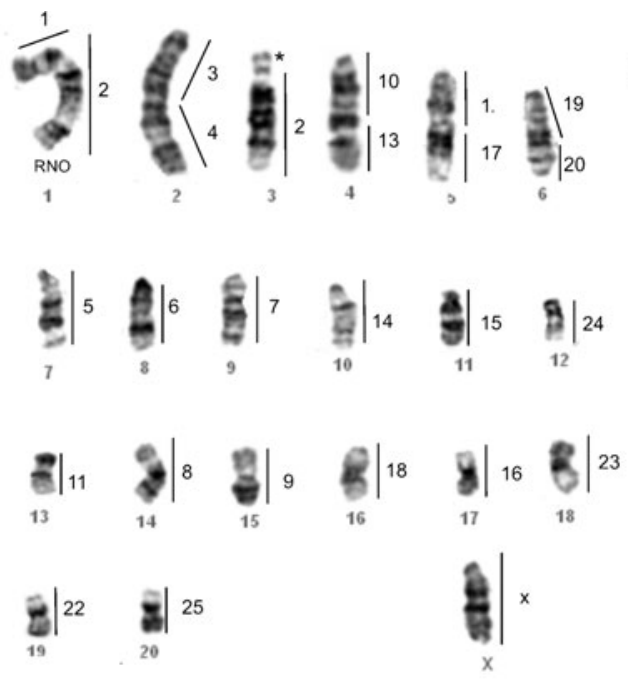

(b)

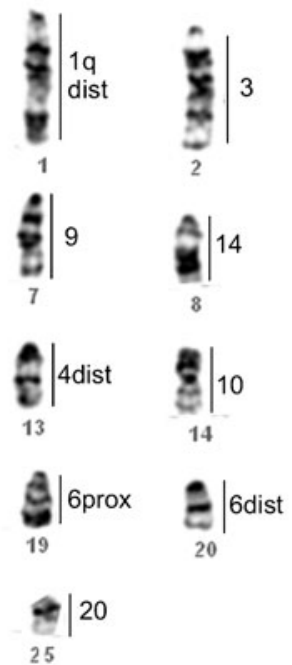

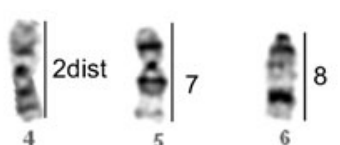

5
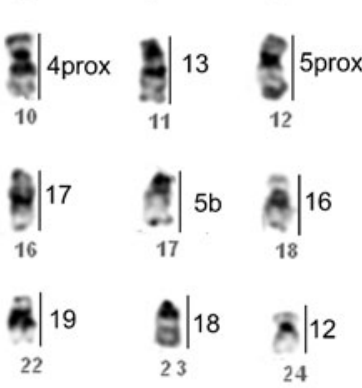

18
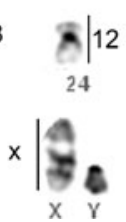

Fig. 5 a Regions of orthology between $R$. norvegicus $(2 n=42)$, and $M$. surifer $(2 n=52)$ chromosomes based on reciprocal chromosome painting and mapped to the $R$. norvegicus Gbanded half-karyotype $(2 n=42)$. Segments orthologous to $M$. surifer are shown on the right. b G-banded half-karyotype of male $M$. surifer $(2 n=52)$ with regions of orthology to $R$.

norvegicus (numbered on the right, except for $\mathrm{X}$ ) as determined by cross-species chromosome painting. Asterisk indicates blocks that were not hybridized by any of the chromosome paints and which correspond to heterochromatic regions identified through C-banding (Badenhorst et al. 2009) 
Chromosome painting using MSU and RNO probes onto other Rattini species

Cross-species chromosome painting using RNO and MSU probes was successfully performed on $R$. exulans, R. losea, R. tanezumi, B. savilei, B. berdmorei, B. bowersi, L. edwardsi and N. fulvescens. The half-karyotype comparisons of G-banded chromosomes of the nine species under investigation in this study compared to that of $R$. norvegicus is presented in Fig. 6, and examples of Zoo-FISH among the different species using $R$. norvegicus chromosomes are provided in supplementary material S4. The hybridization results are summarized in Table 4. Briefly, 16 of 21 pairs of chromosomes are conserved in toto in the nine Rattini genomes investigated in the present study (i.e. pairs orthologous to RNO 3, 7-20 and X). However, comparisons of the G-banding patterns showed a number of
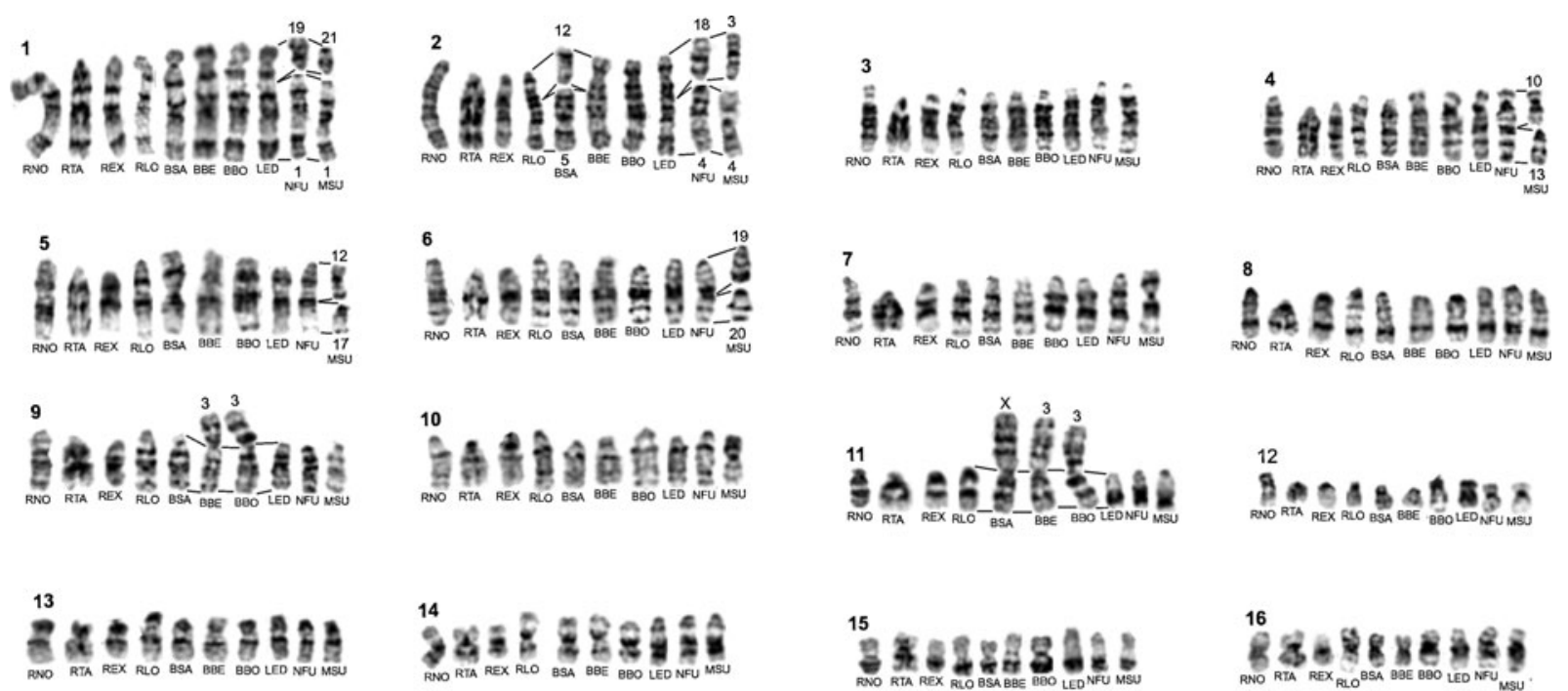

15
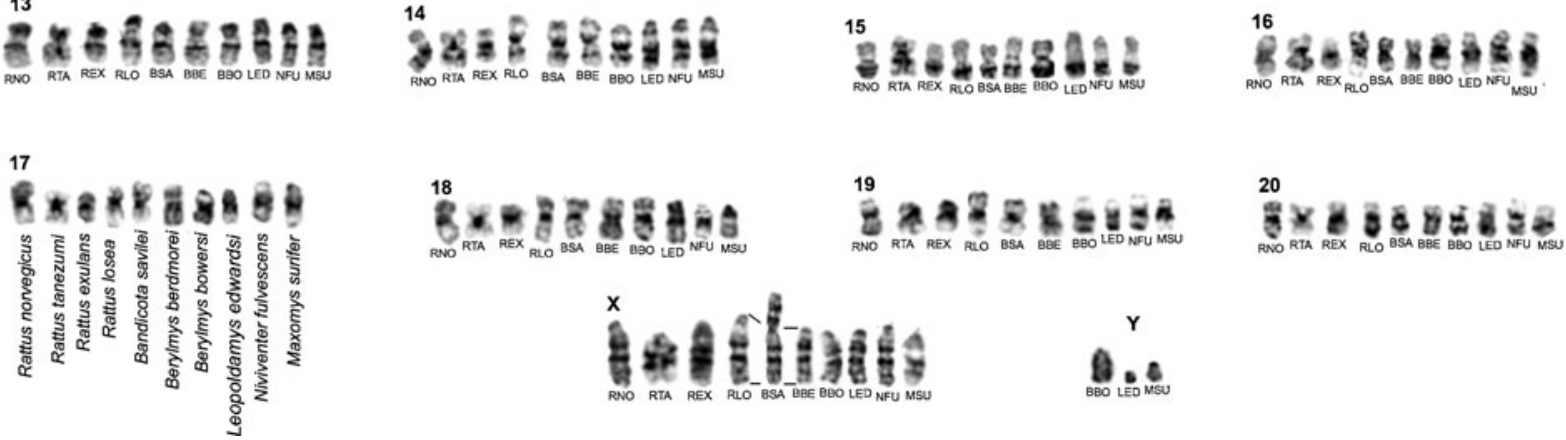

Fig. 6 G-banded half-karyotype comparison between $R$. norvegicus and the nine species analysed in this study showing genome-wide chromosomal correspondence defined by painting (using $R$. norvegicus and $M$. surifer chromosome paints) and banding homologies. Karyotypes were arranged according to $R$. norvegicus standard karyotype (committee for a standardized karyotype of $R$. norvegicus, 1973) 
Table 4 Conserved chromosomal regions detected in Rattini species using RNO painting probes

\begin{tabular}{|c|c|c|c|c|c|c|c|c|c|}
\hline R. norvegicus & R. losea & R. tanezumi & R. exulans & B. bowersi & B. berdmorei & B. savilei & L. edwardsi & N. fulvescens & M. surifer \\
\hline 1 & 1 & 1 & 1 & 1 & 1 & 1 & 2 & 19,1 & 21,1 \\
\hline 2 & 2 & 2 & 2 & $2+$ & $2+$ & $5+, 12$ & $1+$ & 18,4 & $3,4+$ \\
\hline 3 & 3 & 3 & 3 & 4 & 4 & 4 & 4 & 3 & 2 \\
\hline 4 & 4 & 4 & 4 & $6+$ & $6+$ & 2 & $3+$ & $2+$ & $10+, 13$ \\
\hline 5 & 5 & 5 & 5 & $5+$ & $5+$ & $3+$ & 5 & 5 & $12+, 17$ \\
\hline 6 & 6 & 6 & 6 & 7 & 7 & 6 & 6 & 6 & 19,20 \\
\hline 7 & 7 & 7 & 7 & 8 & 8 & 7 & 7 & 7 & $5+$ \\
\hline 8 & 8 & 8 & 8 & 10 & 10 & 8 & 8 & 8 & 6 \\
\hline 9 & 9 & 9 & 9 & 3 & 3 & $9+$ & 13 & 9 & 7 \\
\hline 10 & 10 & 10 & 10 & 9 & 9 & 10 & 10 & 10 & $14+$ \\
\hline 11 & 11 & 11 & 11 & 3 & 3 & $\mathrm{X}$ & $17+$ & $16+$ & $15+$ \\
\hline 12 & 12 & 12 & 12 & 19 & 19 & 20 & 20 & 22 & 12 \\
\hline 13 & 13 & 13 & 13 & 11 & 11 & 11 & 11 & 11 & 11 \\
\hline 14 & 14 & 14 & 14 & 12 & 12 & 13 & $9+$ & $12+$ & $14+$ \\
\hline 15 & 15 & 15 & 15 & 13 & 13 & 15 & $12+$ & $13+$ & $15+$ \\
\hline 16 & 16 & 16 & 16 & 16 & 15 & 14 & $14+$ & $14+$ & $16+$ \\
\hline 17 & 17 & 17 & 17 & 15 & 16 & 16 & $15+$ & $15+$ & $17+$ \\
\hline 18 & 18 & 18 & 18 & 14 & 14 & 17 & $16+$ & $17+$ & $18+$ \\
\hline 19 & 19 & 19 & 19 & 17 & 17 & 18 & 18 & 20 & $22+$ \\
\hline 20 & 20 & 20 & 20 & 18 & 18 & 19 & 19 & 21 & $20+$ \\
\hline$X$ & XX & $\mathrm{XX}$ & XX & $X$ & $X$ & $X$ & $X$ & XX & $X$ \\
\hline $\mathrm{Y}$ & & & & $\mathrm{Y}$ & & & $\mathrm{Y}$ & & $\mathrm{Y}$ \\
\hline
\end{tabular}

Intrachromosomal rearrangements identified following comparisons with their respective $R$. norvegicus orthologues are denoted by +

fused with the original $\mathrm{X}$ (supplementary material S4). All interchromosomal rearrangements were confirmed through the hybridization of $M$. surifer paints (supplementary material S1), except for the disruption of RNO 2 (previously addressed).

Mapping the chromosomal rearrangements onto a Rattini consensus molecular tree

The mapping of G-banding and Zoo-FISH data to the Rattini consensus tree permitted the identification of ten synapomorphies, seven autapomorphies and three potentially homoplasic characters. Two synapomorphies were retrieved that unite Rattini, namely the segmental association of RNO 7prox+7dist (RNO 7) and RNO 16prox+16dist (RNO 16) (Fig. 1). Inversions of RNO 19 and 20 unite the Rattini representatives to the exclusion of $M$. surifer. Six synapomorphies were retrieved supporting the grouping of Rattus (R. losea; R. tanezumi and R. exulans),
B. savilei, B. bowersi and B. berdmorei (inversions of RNO 11 and RNO 14-18). Five autapomorphies were identified in $M$. surifer (fissions of RNO 4 to 6, inversions of RNO 10 and 16) and a single autapomorphy was present in $R$. rattus (RRA), Rb 5;7. The remaining autapomorphy involved a sex-autosome translocation in $B$. savilei comprising the $R$. norvegicus orthologues RNO X and 11. Close scrutiny of the three potentially homoplasic rearrangements identified by FISH analysis (the fusion of $1 \mathrm{p} / 1 \mathrm{q}$ prox $+1 \mathrm{q}$ dist, 2prox +2 dist and $\mathrm{Rb} 9 ; 11$ ) suggests that two are hemiplasic (Avise and Robinson 2008) and one, the $\mathrm{Rb}$ 9;11 fusion is a true homoplasy.

\section{Discussion}

Cross-species painting using $R$. norvegicus whole chromosome paints together with reciprocal painting between $R$. norvegicus and $M$. surifer and compar- 
isons of the various G-banding patterns facilitated the generation of genome-wide comparative maps among nine Rattini species (Fig. 1). In total, six different murine genera were investigated in this studyBandicota, Leopoldamys, Rattus, Berylmys, Niviventer and Maxomys. These comparative maps, together with published data (from $R$. rattus and representatives of Murini, Arvicanthini and Apodemini), allowed the tracking of chromosomal rearrangements that have occurred during the evolution of Rattini. This permitted an assessment of their usefulness in discriminating phylogenetic relationships among species and the construction of the putative RAK.

Mode and tempo of chromosomal evolution within Rattini

Karyotypes may differ by many chromosome rearrangements, often evident among species within the same family (for example the Muridae). However, although at least 19 chromosome rearrangements (fusions, fissions and pericentric inversions) have occurred within Rattini, the variation is somewhat muted when one takes each species/lineage separately into account (Fig. 1). Although the rate of chromosomal change is low in most Rattini branches $(\leq 0.6$ rearrangements per million years, represented hereafter as R/my), this is far from even. For example, there is evidence of an elevated rate on the branch leading to the common ancestor of Berylmys, Bandicota and Rattus assemblage (node B) that entails six pericentric inversions that were fixed within a short time period $(\sim 1.8 \mathrm{my})$. This rapid rate of change $\left(3.33 \mathrm{my}^{-1}\right.$ ) was followed by a period of stasis, the only exceptions being a single fusion shared by $B$. bowersi and B. berdmorei, the fixation of fission and the origin of a sex/autosome fusion in B. savilei and two fusions which restructured the $R$. rattus karyotype. As a consequence, the Rattini appear to exhibit a high degree of genomic conservation and, if inversions were excluded, L. edwardsi and Rattus (R. losea; R. tanezumi and $R$. exulans) have retained largely invariant karyotypes since their last common ancestor $\sim 7$ million years ago (mya). This is in sharp contrast to some other murids - for example, Nannomys, Mus, Coelomys and Pyromys (Veyrunes et al. 2006)-emphasizing that chromosomal rearrangements in Rattini do not closely track speciation events.
A more detailed comparison of the slow rate of chromosomal change in Rattini with other rodents is informative. For example, the four subgenera of Mus that diverged within $\sim 1$ my (between 7.5 and 6.5 mya) are represented by a rate of 13 mutations per million years (Veyrunes et al. 2006). Moreover, 16 $\mathrm{Rb}$ fusions became fixed in the M. minutoides clade in less than 1 million years (Veyrunes et al. 2010). Similarly, the recently diverged West African gerbilline Taterillus species have undergone extremely rapid rates of chromosome evolution being characterised by a rate of 45 changes per my (Dobigny et al. 2002a; 2005). This contrasts with non-murid rodents such as squirrels (Sciuridae), where karyotypes (i.e. Menetes berdmorei, Sciurus carolinensis and Callosciurus erythraeus; Richard et al. 2003; Stanyon et al. 2003; Li et al. 2004, 2006) show extensive conservation with that of human (i.e. $\sim 0.3 \mathrm{R} / \mathrm{my}$ ). This underscores the well-established observation that chromosomal evolution can vary between lineages (Rattini, conserved vs. Murini, rearranged). The pattern of slow chromosomal evolution in Rattini is also reflected in the analysis of repetitive elements (rat sat I DNA, telomeres and NORs) which were found to be largely conserved with respect to distribution and location (see above).

Although our investigation identified two types of rearrangements that are common in mammals (fusions and fissions), it was in fact changes to the short arms of many autosomes (considered to be pericentric inversions) that predominate in the karyotypic evolution of Rattini, echoing earlier observations by Gadi and Sharma (1983). Pericentric inversions were unambiguously confirmed by BAC-mapping in $R$. tanezumi, one of the species which exhibits short-arm variability in chromosomes orthologous to RNO 1, 12 and 13, and it seems reasonable to assume that this similarly applies to other short-arm variants in Rattus (other species that show these heteromorphisms are $R$. rattus, $R$. norvegicus, $R$. exulans, $R$. losea, $R$. annadalei and $R$. muelleli). The most obvious explanation for this is that the inversions were polymorphic in their last common ancestor (the deepest divergence in Rattus is dated at $\sim 3.5$ mya, and that of $R$. norvegicus, the most basal of the species analysed in our study, at $\sim 2.9$ mya, Robins et al. 2008), and have since persisted as polymorphisms in each lineage (i.e. reflecting incomplete lineage sorting; see discussion on hemiplasic characters 
below). Alternative explanations involving independently acquired inversions (or centromeric shifts and transpositions, rearrangements that could similarly account for the observed morphological differences) in species other than $R$. tanezumi are considered unlikely on grounds of parsimony. Should this hypothesis hold, it may be that these inversions have an adaptive role promoting rapid genetic diversification among populations through repressed recombination thus preventing admixture of the newly evolved combinations of alleles (Noor et al. 2001; Hoffman et al. 2004; Ayala and Coluzzi 2005; Brown and $\mathrm{O}^{\prime} \mathrm{Neill} 2010$ and references therein). It has been postulated that these processes may explain the association of balanced inversion clines along adaptive gradients (e.g. Bonvicino et al. 2001; Noor et al. 2001; Coluzzi et al. 2002; Stefansson et al. 2005). Interestingly Yosida (1980) postulated that a pericentric inversion in the acrocentric pair 1 of an insular Asian black rat population in Southeast Asia, most likely $R$. tanezumi $(2 n=42)$, appeared to confer a selective advantage to the survival of carriers in warmer climates. Although appealing, interpretations of the geographic patterns and the possible adaptive value of inversion polymorphisms in these rodents are problematic, in part due to questionable taxonomic divisions in several species, and the confounding effects of human transportation of Rattus species (i.e. $R$. exulans) across geographic boundaries.

\section{Cytogenetic signatures for Rattini}

1. Autosomal characters: Cytogenetic signatures that support some of the natural groupings at higher systematic levels were retrieved in this study. For example, the syntenic associations 7 prox +7 dist and $16 a+16 b$ that gave rise to RNO 7 and RNO 16, respectively, were identified as potentially defining Rattini. However, the $16 \mathrm{a}+16 \mathrm{~b}$ association should be considered provisional until reciprocal painting in a wider range of species is completed.

The monophyly of $B$. bowersi, B. berdmorei, $B$. savilei and Rattus (Fig. 1) is supported by six pericentric inversions. This is consistent with an earlier report that posits pericentric inversions played a key role in the karyotype evolution of Rattus and Bandicota (Gadi and Sharma 1983). In contrast, the sister grouping of $N$. fulvescens $+L$. edwardsi suggested by sequence data, was not supported by chromosomal characters (Fig. 1). This gives credence to an earlier report that $L$. edwardsi is chromosomally more closely related to Berylmys, Bandicota and Rattus, than it is to Niviventer (Gadi and Sharma 1983).

Of the three potentially homoplasic characters identified in our study (the fusion of $1 \mathrm{p} / 1 \mathrm{q}$ prox $+1 \mathrm{q}$ dist, 2prox +2dist and Rb 9; 11), the most parsimonious explanation based on the dates and patterns of occurrence on the tree is that two are hemiplasies (the $1 \mathrm{p} / 1 \mathrm{q}$ prox $+1 \mathrm{q}$ dist and 2 prox +2 dist syntenies) and one $(\mathrm{Rb} 9 ; 11)$ a true homoplasy (Fig. 1). Hemiplasy (Avise and Robinson 2008) is considered likely when the internodes are short and the polymorphism persists for relatively short time periods ( $\sim 3$ my; Stefansson et al. 2005, Robinson et al. 2008, Robinson and Ropiquet 2011 and MacEachern et al. 2009 suggest 5-8 my for the lineage sorting of polymorphic sites in autosomal genes). Under hemiplasy, both the $1 \mathrm{p} / 1 \mathrm{q}$ prox $+1 \mathrm{q}$ dist and 2 prox +2 dist syntenies were present as polymorphic rearrangements at node $\mathrm{A}$ and the alternative forms were fixed idiosyncratically in different species. Based on their distribution on the tree (Fig. 1) the 1p/1q prox $+1 \mathrm{q}$ dist fusion/fission polymorphism would be required to minimally persist for 1.5 my ( 7.2-5.7 my), and the 2 prox + 2dist fusion/fission polymorphism for $3.2 \mathrm{my}$ ( 7.2-4.0 my). In contrast, the fusion $9+11$ is considered a true homoplasy (i.e. it arose convergently in the common ancestor to $B$. bowersi $+B$. berdmorei, and in $R$. rattus) given the protracted period required for its persistence ( $\sim 5 \mathrm{my}$ ).

2. Gonosomal characters: An X chromosomeautosome translocation was identified in $B$. savilei involving a fusion of RNO X and 11. This type of rearrangement is generally considered to be highly deleterious due to the effects of X-inactivation on the autosomal component of the fusion chromosome and the differing replication times of the two (Dobigny et al. 2004b). It has been postulated that an interstitial heterochromatic block (IHB) between the $\mathrm{X}$ chromosome and the autosomal segment can act as a barrier thus preventing the spread of inactivation across the $\mathrm{X} /$ autosomal boundary. Interstitial heterochromatic blocks are consequently thought to represent a "regulatory superstructure" for the differential timing of replication (Dobigny et al. 2004b) and, given the 
presence of the IHB detected in the B. savilei $\mathrm{X}$ chromosome (see Badenhorst et al. 2009), this epigenomic hypothesis would apply.

3. Nucleolar organizer regions: The contention that NORs are useful phylogenetic markers for species delimitation (see for example Matsubara et al. 2004; Nguyen et al. 2008; Wang et al. 2009) does not hold in the Rattini since the NORs were conserved across divergent species (i.e. principally on the orthologues of RNO 3, 4, 6, 8, 9, 10 and 12, Table 3). Even the NORs on the orthologues of RNO 11 that appeared to unite $R$. exulans, $R$. losea, $R$. tanezumi and $R$. norvegicus to the exclusion of the other taxa proved unsatisfactory in a broader phylogenetic context following the inclusion of $R$. rattus (Table 3). This highlights several important considerations when using these chromosomal landmarks as cytogenetic markers for species discrimination (reviewed in Dobigny et al. 2004a). The first is that intraspecific NOR variation, a well-known phenomenon in mammals, necessitates adequate sample sizes and geographically representative sampling before solid conclusions on number and location can be reached. This is particularly relevant to the present study since Yosida (1979), Sasaki et al. (1986) and Wang et al. (2003) have documented intraspecific variation in NOR number and position in both Rattus and Niviventer. Secondly, silver staining (used here) will only detect active NORs and may also reveal non-ribosomal loci (see examples for hedgehogs, Sanchez et al. 1995, and gerbils, Dobigny et al. 2002b). Analysis by FISH, which would address the non-specificity of silver staining (Sanchez et al. 1995), was attempted (5S rRNA and 28S rRNA genes isolated from gDNA) but was unsuccessful. Nonetheless, even with the use of single specimens and the limitations associated with silver staining, our results show a surprising conservation of NORs among Rattini species for which comparable data exist (i.e. Szabo et al. 1978; Kodama et al. 1980; Sasaki et al. 1986; Cavagna et al. 2002) and provide novel baseline information for taxa where these data are lacking (M. surifer, L. edwardsi, N. fulvescens, B. savilei, $B$. berdmorei and B. bowersi).

4. Satellite I DNA: Analysis (physical mapping and molecular analyses) of another repetitive element, the rat sat I DNA family, demonstrated a complete lack of homology between sequences isolated from non-Rattus species ( $N$. fulvescens, B. savilei and $B$. berdmorei) and $R$. norvegicus sat I DNA. We interpret the interspersed pattern detected in the non-Rattus taxa as reflecting either a technical artefact (i.e. mispriming) or, alternatively, that the sat I primers used amplified long interspersed nuclear elements (LINE-1), or something that might cross hybridize to LINE-1 (see Waters et al. 2004). The rat sat I DNA family was, however, highly conserved within Rattus ( $R$. exulans, $R$. losea and R. tanezumi; $>90 \%$ sequence similarity), which was corroborated by TRF analysis (tandem repeated 92 bp subunit, $>75 \%$ pair-wise sequence similarity, corresponding to the previously described $92 \mathrm{bp}$ repeat subunit for $R$. norvegicus sat I DNA by Pech et al. 1979). Interestingly, although the rat sat I DNA family is reported to concentrate in the centromeric DNA of $R$. norvegicus (see Sternes and Vig, 1995; see also supplement material S2present study), there is variability in its location in Rattus (i.e. all $R$. norvegicus chromosomes carry

\section{Rattini Ancestral Karotype $(2 n=46)$}
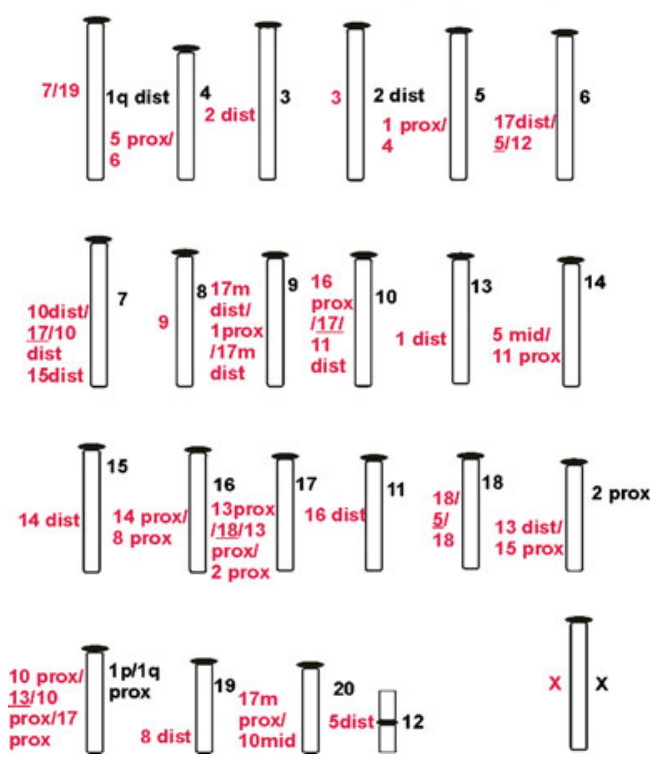

Fig. 7 Putative ancestral karyotype of Rattini with $R$. norvegicus and M. musculus homologies numbered on the right (black) and left (red), respectively. Underlined M. musculus segments represent small, generally undetected conserved segments between mouse and rat. dist, mid, prox, $m$ prox refer to the distal, middle, proximal and mid proximal segments of the chromosomes, respectively 
centromeric sat I DNA, while only eight pairs of chromosomes in $R$. tanezumi show this; supplementary material S2). Additionally, satDNA hybridization signals were undetected on chromosomes 12 and 13 in R. losea and chromosome 1 in R. exulans. The variable distribution and signal intensity of satDNA in Rattus is not unique since satDNA has been found to vary with regards to its abundance, sequence and chromosomal distribution between other closely related species (Adega et al. 2008; Louzada et al. 2008; Acosta et al. 2010).

Although some studies have suggested that Bandicota may be congeneric with Rattus (see Verneau et al. 1997, 1998), the analysis of repetitive elements discussed above does not support this. For example the B. savilei sequence showed no meaningful homology with rat sat I DNA following physical mapping and molecular analyses. These findings, together with the conservation of satellite sequence within Rattus suggest rather that the rat sat I DNA family is Rattus-specific. If so it provides an opportunity to date the appearance of the repeat in this group of rodents. Molecular clock estimates place the deepest divergence within Rattus at $\sim 3.5$ mya and $R$. norvegicus is thought to have diverged $\sim 2.9$ mya (Robins et al. 2008). It seems likely, therefore, that its presence in the common ancestor to Rattus at $\sim 3.5$ mya reflects the minimum age of this satellite family, and its localization at the centromeres in species of Rattus and its absence in taxa outside of this assemblage may be consistent with a feedback model of satellite evolution (Nijman and Lenstra 2001; reviewed in Slamovits and Rossi 2002). Based on this model, the new rat sat I DNA family is considered to be undergoing the initial phase of its evolutionary history as the three Rattus satDNA sequences ( $R$. tanezumi, $R$. losea and $R$. exulans) currently display a high degree of conservation ( $>90 \%$ sequence similarity) with $R$. norvegicus. (Each phase is characterised by different levels of sequence identity where the initial phase is favoured by sequence homogeneity).

The Rattini ancestral karyotype

The mapping of polarized chromosomal characters allowed an objective assessment of ancestral states for the reconstruction of the putative RAK (Fig. 7). The analyses presented herein suggest that the RAK had $2 n=46$ and this comprised, with one exception (a single small metacentric pair), only acrocentric chromosomes. Moreover, it shares 16 autosomal pairs that were conserved in toto (entire block or syntenic segment: MMU 7/19, 10prox/17prox, 13dist/15prox, 3, 2dist, 5prox/6, 1prox/4, 9, 16dist, 5dist, 1dist, 5med/11prox, 14dist, 13prox/2prox, 18 and 8 dist) with the $2 n=46$ acrocentric ancestral Mus karyotype proposed by Veyrunes et al. (2006).

\section{Concluding comments}

This study presents a karyotypic investigation of Rattini that includes species that are representative of six of the 34 recognized genera. The data show that chromosome evolution in these rodents was driven largely by pericentric inversions. We also report a novel X-autosome translocation in B. savilei, a rearrangement hitherto undetected within Rattini. The overwhelming pattern of chromosomal evolution in these rodents is one of constrained change. This, together with the suggestion that the rat genome is structurally closer to that of human than is the mouse (see Zhao et al. 2004), underscores the usefulness of the rat as a model species in some comparative genomic studies. Consequently, the Rattini ancestral karyotype presented here (the first comprehensive hypothesis of the putative RAK) may prove useful in directing the selection of rodent species for future large-scale investigations of genome organization.

Acknowledgements Financial assistance from the South African National Research Foundation (NRF) to TJR and a joint research grant (PROTEA programme, no. 07F42SA) awarded under a France/South Africa scientific cooperation agreement to TJR and GD are gratefully acknowledged. DB was supported, in part, by an NRF Scarce Skills Bursary. This investigation forms part of the ANR-00121-05 programme 'Biodiversity of rodentborne hantaviruses in Southeast Asia' (coord. J.P. Hugot, 20062008). Researchers in this programme (Yannick Chaval, Serge Morand, Vincent Herbreteau and collaborators) kindly provided the specimens analysed in this study.

\section{References}

Acosta MJ, Marchal JA, Fernández-Espartero C et al (2010) Characterisation of the satellite DNA Msat-160 from species of Terricola (Microtus) and Arvicola (Rodentia, Arvicolinae). Genetica 138:1085-1098

Adega F, Chaves R, Guedes-Pinto H (2008) Suiformes orthologous satellite DNAs as a hallmark of collared and white- 
lipped peccaries (Tayassuidae) evolutionary rearrangements. Micron 39:1281-1287

Aitman TJ, Critser JK, Cuppen E et al (2008) Progress and prospects in rat genetics: a community view. Nat Genet 40:516-522

Aplin KP, Chesser T, Have JT (2003) Evolutionary biology of the genus Rattus: profile of an archetypal rodent pest. In: Singleton GR, Hinds LA, Krebs CJ (eds) Rats, mice and people: rodent biology and management. ACIAR Monograph No. 96. Australian Centre for International Agricultural Research, pp 487-498

Avise JC, Robinson TJ (2008) Hemiplasy: a new term in the lexicon of phylogenetics. Syst Biol 57:503-507

Ayala FJ, Coluzzi M (2005) Chromosome speciation: humans, Drosophila, mosquitoes. Proc Natl Acad Sci USA 102:6535-6542

Badenhorst D (2011) Rattini (Rodentia, Murinae) species relationships and involvement as reservoirs for scrub typhus: a comparative molecular cytogenetic and gene expression approach. $\mathrm{PhD}$ thesis, University of Stellenbosch: Stellenbosch University Press

Badenhorst D, Herbreteau V, Chaval Y et al (2009) New karyotypic data for Asian rodents (Rodentia, Muridae) with the first report of B-chromosomes in the genus Mus. J Zool (Lond) 279:44-56

Barch MJ (1997) The AGT cytogenetics laboratory manual. Lippincott-Raven Publishers, Philadelphia, p 301

Bastos ADS, Nair D, Taylor PJ et al (2011) Genetic monitoring detects an overlooked cryptic species and reveals the diversity and distribution of three invasive Rattus congeners in South Africa. BMC Genet 12:26

Benson G (1999) Tandem repeats finder: a program to analyze DNA sequences. Nucleic Acids Res 27:573-580

Bolzan AD, Bianchi MS (2006) Telomeres, interstitial telomeric repeat sequences, and chromosomal aberrations. Mut Res 612:189-214

Bonvicino C, D'Andrea P, Borodin P (2001) Pericentric inversion in natural populations of Oligoryzomys nigripes (Rodentia, Sigmodontinae). Genome 44:791-796

Brown JD, O'Neill RJ (2010) Chromosomes, conflict, and epigenetics: chromosomal speciation revisited. Annu Rev Genomics Hum Genet 11:291-316

Cavagna P, Stone G, Stanyon R (2002) Black rat (Rattus rattus) genomic variability characterised by chromosome painting. Mamm Genome 13:157-163

Chaves R, Adega F, Santos S, Guedes-Pinto H, Heslop-Harrison JS (2002) In situ hybridization and chromosome banding in mammalian species. Cytogenet Genome Res 96:113-116

Chaves R, Adega F, Heslop-Harrison JS, Guedes-Pinto H, Wienberg J (2003a) Complex satellite DNA reshuffling in the polymorphic t $(1 ; 29)$ Robertsonian translocation and evolutionary derived chromosomes in cattle. Chromosome Res 11:641-648

Chaves R, Adega F, Wienberg J, Guedes-Pinto H, HeslopHarrison JS (2003b) Molecular cytogenetic analysis and centromeric satellite organization of a novel 8;11 translocation in sheep: a possible intermediate in biarmed chromosome evolution. Mamm Genome 14:706-710

Coluzzi M, Sabatini A, Della Torre A, Di Deco M, Tetrarca V (2002) A polytene chromosome analysis of the Anopheles gambiae species complex. Science 298:1415-1418
Dobigny G, Aniskin V, Volobouev V (2002a) Explosive chromosome evolution and speciation in the gerbil genus Taterillus (Rodentia, Gerbillinae): a case of two new cryptic species. Cytogenet Genome Res 96:117-124

Dobigny G, Ozouf-Costaz C, Bonillo C, Volobouev V (2002b) "Ag-NORs" are not always true NORs, new evidence in mammals. Cytogenet Genome Res 98:75-77

Dobigny G, Ducroz J, Robinson TJ, Volobouev V (2004a) Cytogenetics and cladistics. Syst Biol 53:470-484

Dobigny G, Ozouf-Costaz C, Bonillo C (2004b) Viability of X autosome translocations in mammals: an epigenomic hypothesis from a rodent case-study. Chromosoma 113:34-41

Dobigny G, Aniskin V, Granjon L, Cornette R, Volobouev V (2005) Recent radiation in West African Taterillus (Rodentia, Gerbillinae): the concerted role of chromosome and climatic changes. Heredity 95:358-368

Gadi IK, Sharma T (1983) Cytogenetic relationships in Rattus, Cremnomys, Millardia, Nesokia and Bandicota (Rodentia: Muridae). Genetica 61:21-40

Gilbert C, O'Brien PCM, Bronner G et al (2006) Chromosome painting and molecular dating indicate a low rate of chromosomal evolution in golden moles (Mammalia, Chrysochloridae). Chromosome Res 14:793-803

Goodpasture C, Bloom SE (1975) Visualization of nucleolar organizer regions in mammalian chromosmes using silver stain. Chromosoma 53:37-50

Grutzner F, Himmelbauer H, Paulsen M, Ropers HH, Haaf T (1999) Comparative mapping of mouse and rat chromosomes by fluorescence in situ hybridization. Genomics 55:306-313

Guilly M, Fouchet P, de Chamisso P, Schmitz A, Dutrillaux B (1999) Comparative karyotype of rat and mouse using bidirectional chromosome painting. Chromosome Res $7: 213-221$

Hall TA (1999) BioEdit: a user-friendly biological sequence alignment editor and analysis program for Windows 95/98/ NT. Nucl Acids Symp Ser 41:95-98

Hamta A, Adamovic T, Samuelson E, Helou K, Behboudi A, Levan G (2006) Chromosome ideograms of the laboratory rat (Rattus norvegicus) based on high- resolution banding, and anchoring of the cytogenetic map to the DNA sequence by FISH in sample chromosomes. Cytogenet Genome Res 115:158-168

Helou K, Walentinsson A, Levan G, Stahl F (2001) Between rat and mouse zoo-FISH reveals 49 chromosomal segments that have been conserved in evolution. Mamm Genome 12:765-771

Hoffman AA, Sgro CM, Weeks AR (2004) Chromosomal inversion polymorphisms and adaptation. Trends Ecol Evol 19:483-488

Ijdo JW, Wells RA, Baldini A, Reeders ST (1991) Improved telomere detection using a telomere repeat probe (TTAGGG) n generated by PCR. Nucleic Acids Res 19:4780

Jansa SA, Weksler M (2004) Phylogeny of muroid rodents: relationships within and among major lineages as determined by IRBP gene sequences. Mol Phylogenet Evol 31:256-276

Kodama Y, Yoshida M, Sasaki M (1980) An improved silver staining technique for nucleolus organizer regions by using nylon cloth. Jap J Human Genet 25:229-233 
Lecompte E, Aplin K, Denys C, Catzeflis F, Chades M, Chevret P (2008) Phylogeny and biogeography of African Murinae based on mitochondrial and nuclear gene sequences, with a new tribal classification of the subfamily. BMC Evol Biol 8:199

Lee MR, Elder FFB (1980) Yeast stimulation of bone marrow mitosis for cytogenetic investigations. Cytogenet Cell Genet 26:36-40

Li T, O'Brien PCM, Biltueva L et al (2004) Evolution of genome organizations of squirrels (Sciuridae) revealed by cross-species chromosome painting. Chromosome Res 12:317-335

Li T, Wang J, Su W, Nie W, Yang F (2006) Karyotypic evolution of the family Sciuridae: inferences from the genome organizations of ground squirrels. Cytogenet Genome Res 112:270-276

Louzada S, Paco A, Kubickova S et al (2008) Different evolutionary trails in the related genomes Cricetus cricetus and Peromyscus eremicus (Rodentia, Cricetidae) uncovered by orthologous satellite DNA repositioning. Micron 39:1149-1155

MacEachern S, McEwan J, Goddard M (2009) Phylogenetic reconstruction and the identification of ancient polymorphism in the Bovini tribe (Bovidae, Bovinae). BMC Genomics 10:177. doi:10.1186/1471-2164-10-177

Matisoo-Smith E, Robins JH (2004) Origins and dispersals of Pacific peoples: evidence from mtDNA phylogenies of the Pacific rat. Proc Natl Acad Sci 101:9167-9172

Matsubara K, Nishida-Umehara C, Tsuchiya K, Nukaya D, Matsuda Y (2004) Karyotypic evolution of Apodemus (Muridae, Rodentia) inferred from comparative FISH analyses. Chromosome Res 12:383-395

Meerburg B, Singleton G, Kijlstra A (2009) Rodent-borne diseases and their risks for public health. Crit Rev Microbiol 35:221-270

Nguyen TT, Aniskin VM, Gerbault-Seureau M et al (2008) Phylogenetic position of the saola (Pseudoryx nghetinhensis) inferred from cytogenetic analysis of eleven species of Bovidae. Cytogenet Genome Res 122:41-54

Nijman IJ, Lenstra JA (2001) Mutation and recombination in cattle satellite DNA: a feedback model for the evolution of satellite DNA repeats. J Mol Evol 52:361-371

Nilsson S, Helou K, Walentinsson A, Szpirer C, Nerman C, Stahl F (2001) Rat-mouse and rat-human comparative maps based on gene homology and high-resolution zoo-FISH. Genomics 74:287-298

Noor MAF, Grams KL, Bertucci LA, Reiland J (2001) Chromosomal inversion and the reproductive isolation of species. Proc Natl Acad Sci USA 98:12084-12088

Pagès M, Chaval Y, Herbreteau V et al (2010) Revisiting the taxonomy of the Rattini tribe: a phylogeny-based delimitation of species boundaries. BMC Evol Biol 10:184

Pech M, Igo-Kemenes T, Zachau HG (1979) Nucleotide sequence of a highly repetitive component of rat DNA. Nucleic Acids Res 7:417-432

Richard F, Messaoudi C, Bonnet-Garnier A, Lombard M, Dutrillaux B (2003) Highly conserved chromosomes in an Asian squirrel (Menetes berdmorei, Rodentia: Sciuridae) as demonstrated by ZOO-FISH with human probes. Chromosome Res 11:597-603

Robins JH, McLenachan PA, Phillips MJ, Craig L, Ross HA, Matisoo-Smith E (2008) Dating of divergences within the
Rattus genus phylogeny using whole mitochondrial genomes. Mol Phylogenet Evol 49:460-466

Robinson TJ, Ropiquet A (2011) Examination of hemiplasy, homoplasy and phylogenetic discordance in chromosomal evolution of the Bovidae. Syst Biol. doi:10.1093/sysbio/syr045

Robinson TJ, Ruiz-Herrera A, Avise JC (2008) Hemiplasy and homoplasy in the karyotypic phylogenies of mammals. Proc Natl Acad Sci USA 105:14477-14481

Sanchez A, Jimenez R, Burgos M, Stitou S, Zurita F, Diaz de la Guardia R (1995) Cytogenetic peculiarities in the Algerian hedgehog: silver stains not only NORs but also heterochromatic blocks. Heredity 75:10-16

Sasaki M, Nishida C, Kodama Y (1986) Characterisation of silver-stained nucleolus organizer regions (Ag-NORs) in 16 inbred strains of the Norway rat, Rattus norvegicus. Cytogenet Cell Genet 41:83-88

Seabright M (1971) A rapid banding technique for human chromosome. Lancet 2:971-972

Slamovits CH, Rossi M (2002) Satellite DNA: agent of chromosomal evolution in mammals. A review. J Neotrop Mammal 9:297-308

Stanyon R, Yang F, Cavagna P et al (1999) Reciprocal chromosome painting shows that genomic rearrangement between rat and mouse proceeds ten times faster than between humans and cats. Cytogenet Cell Genet 84:150 155

Stanyon R, Stone G, Garcia M, Frönicke L (2003) Reciprocal chromosome painting shows that squirrels, unlike murid rodents, have a highly conserved genome organization. Genomics 82:245-249

Stefansson H, Helgason A, Thorleifsson G et al (2005) A common inversion under selection in Europeans. Nat Rev Genet 37:12-137

Sternes KL, Vig BK (1995) Satellite I DNA in transformed rat cells. Cancer Genet Cytogenet 79:64-69

Szabo P, Lee M, Elder F, Prensky W (1978) Localization of 5S RNA and rRNA genes in the Norway rat. Chromosoma 65:161-172

Taylor PJ, Arntzen L, Hayter M, Iles M, Frean J, Belmain SR (2008) Understanding and managing sanitary risks due to rodent zoonoses in an African city: beyond the Boston Model. Integr Zool 3:38-50

Telenius H, Pelmear A, Tunnacliffe A et al (1992) Cytogenetic analysis by chromosome painting using DOP-PCR amplified sorted chromosomes. Gene Chromosome Canc 4:257-264

Twigger SN, Pruitt KD, Fernández-Suárez XM et al (2008) What everybody should know about the rat genome and its online resources. Nat Genet 40:523-527

Verneau O, Catzeflis F, Furano AV (1997) Determination of the evolutionary relationships in Rattus sensu lato (Rodentia: Muridae) using L1 (LINE-1 amplification events). J Mol Evol 45:424-436

Verneau O, Catzeflis F, Furano AV (1998) Determining and dating recent rodent speciation events by using L1 (LINE-1) retrotransposons. Proc Natl Acad Sci USA 95:11284-11289

Veyrunes F, Dobigny G, Yang F et al (2006) Phylogenomics of the genus Mus (Rodentia; Muridae): extensive genome repatterning is not restricted to the house mouse. Proceedings Proc R Soc B 273:2925-2934 
Veyrunes F, Catalan J, Tatard C et al (2010) Mitochondrial and chromosomal insights into karyotypic evolution of the pygmy mouse, Mus minutoides, in South Africa. Chromosome Res 18:563-574

Wang J, Zhao X, Koh HS, Deng Y, Qi H (2003) Chromosomal polymorphisms due to heterochromatin growth and pericentric inversions in white-bellied rat, Niviventer confucianus, from China. Hereditas 138:59-64

Wang B, Jiang J, Xie F et al (2009) Molecular Phylogeny and Genetic Identification of Populations of Two Species of Feirana Frogs (Amphibia: Anura, Ranidae, Dicroglossinae, Paini) Endemic to China. Zoolog Sci 26:500-509

Waters PD, Dobigny G, Pardini AT, Robinson TJ (2004) LINE1 distribution in Afrotheria and Xenarthra: implications for understanding the evolution of LINE-1 in eutherian genomes. Chromosoma 113:137-144

Wilson DE, Reeder DAM (2005) Mammal species of the world: a taxonomic and geographic reference. The John Hopkins University Press, Baltimore

Wolfe ND, Dunavan CP, Diamond J (2007) Origins of major human infectious diseases. Nature 447:279-283

Yosida TH (1976) Frequencies of chromosome polymorphism (pairs no. 1, 9 and 13) in the black rat, Rattus rattus diardii (Rodentia, Muridae). Chromosoma 36:256-262
Yosida TH (1977) Frequencies of chromosome polymorphisms in pairs no. 1, 9, and 13 in three geographical variants of Black rats, Rattus rattus. Chromosoma 60:391-398

Yosida TH (1979) A comparative study on nucleolus organizer regions (NORs) in 7 Rattus species with special emphasis on the organizer differentiation and species evolution. Proc Jap Acad 55:481-486

Yosida TH (1980) Cytogenetics of the black rat: Karyotype evolution and species differentiation. University of Tokyo Press, Tokyo, pp 1-255

Yosida TH, Sagai T (1975) Variation of C-bands in the chromosomes of several subspecies of Rattus rattus. Chromosoma 50:283-300

Yosida TH, Tsuchiya K, Moriwaki K (1971a) Frequency of chromosome polymorphism in Rattus rattus collected in Japan. Chromosoma 33:33-40

Yosida TH, Tsuchiya K, Moriwaki K (1971b) Karyotypic differences of Black rats, Rattus rattus, collected in various localities of East and Southeast Asia and Oceania. Chromosoma 33:252-267

Zhao S, Shetty J, Hou L et al (2004) Human, mouse, and rat genome large-scale rearrangements: stability versus speciation. Genome Res 14:1851-1860 